\title{
Peculiarities of brain processes during the stop and switch of motor programs among women
}

Olha Korzhyk*,

Olha Pavlovych,

Olha Abramchuk,

Tetyana Kachynska,

Olena Dmytrotsa,

Andriy Poruchynskiy,

Alevtyna Morenko

Department of Human

and Animal Physiology,

Lesya Ukrainka Eastern European

National University,

13 Volya Avenue, Lutsk 43025,

Ukraine
The purpose of the study is to establish differences in the cortical electrical activity among women under conditions of complete inhibition of a running motor program of manual movement (StopSignal paradigm) and under conditions of its inhibition, with subsequent switching to an alternative motor task (Stop-Change paradigm). We used the "event-related desynchronization/synchronization" (ERD/ERS) method. Indicators ERD and ERS were evaluated in the frequency range of EEG $(1-35 \mathrm{~Hz})$ in the frontal, central, and parietal leads. It was established that women demonstrated greater precision in conducting the task in the set with the Stop-Change paradigm than men. In both sets of the experiment, the predominance of ERS events in the range of $\alpha$ - and partially $\beta 1$-activity of EEG is distinguished as a common regularity. Meanwhile, in different sets of the experiment, cortical electrical activity acquired certain specific features of the frequency-spatial organization that could indicate different brain processes during the response to Stop and Stop-Change stimuli. In the set of the use of the Stop-Change paradigm, a higher level of activation processes in the frontal, central, and parietal cortex areas in the EEG $\alpha$ - and $\beta$-activity range is generally showed among women.

Keywords: cerebral cortex, synchronization/desynchronization, manual movements, Stop-Signal paradigm, Stop-Change paradigm, women

\section{INTRODUCTION}

Current technological development of the society, introduction of computerized systems, and the use of information technologies in all spheres of life require active purposeful manual movements (MM). During social interaction, in the process of learning, manufacturing, or simply in everyday situations, people constantly monitor and correct

\footnotetext{
* Corresponding author. Email: olga.korgik@gmail.com
}

their motor behaviour. Manipulator coordination requires permanent cancellation and updating of motor programs and commands. Although specific data on the progress of such processes in the human brain are still very limited, the academic community (Hummel et al., 2002; Pollok et al., 2006) connects MM with significant cortical activity alterations that provide the formation, the launch, and the stoppage of motor programs. The analysis of literature data showed that the modified version of the Go-No Go paradigm, the so-called Stop-Signal paradigm is the mostly widespread fo 
investigating the processes connected with theinhibition of the motor responses (Logan et al., 1984; Verbruggen, Logan, 2008, 2009; Chambers et al., 2009; Ridderinkhof et al., 2010; Aron, 2011). Meanwhile, the so-called Stop-Change paradigm is offered for investigating the physiological mechanisms of inhibition processes, including the motor response in the context of its subsequent alteration to the multiple-choice action (Logan, Burkell, 1986; Verbruggen et al., 2008). Recently, the academic community has become increasingly active in discussing the issues of similar or different mechanisms that provide inhibition of the motor response in the Stop-Signal and the Stop-Change paradigms.

Considering the data on the visualization and the time for the Stop and Change response, Band and van Boxtel (1999), Boecker et al. (2011) indicate the existence of a general way of complete stoppage of the motor response and its stoppage with subsequent replacement of the latter by an alternative reaction. In contrast, other scholars (De Jong et al., 1995; Krämer et al., 2011) insist on the existence of various inhibitory mechanisms. According to their model (De Jong et al., 1995), the inhibition in the situation of the Stop-Signal paradigm usage can be achieved by a quick peripheral mechanism that temporarily stops the execution of all central motor commands. Whereas the inhibition in terms of the Stop-Change paradigm can develop in a slower mode, but the central mechanism can selectively interfere with central single motor commands. The above-mentioned conception is consistent with the version of the inhibition model offered by Aron et al., 2007a, 2007b; Jahfari et al., 2011. According to it, the inhibitory process can take place in two ways: quick hyper-direct (fronto-subtalamic) and indirect (fronto-striatal-pallidal). Aron (2011) suggested that the hyper-direct way is involved in terms of global inhibition and during the selective inhibition an indirect way is activated which considers wider coverage of cortical and subcortical structures during the reverberation of nerve impulses. As a confirmation of the above-mentioned version, Krämer et al. (2011) highlighted the reliable amplitude-temporal differences in the manipu- lating response to the Stop and Change stimuli. Meanwhile, according to the recent researches made by Rangel-Gomez et al. (2015), the process of inhibition during the Change-response was significantly faster than during the Stop-response, but the other amplitude-temporal differences, especially in the frontal and central parts, were not established.

Thus, there is still an open issue of whether the same or different brain mechanisms contribute to the inhibition in the experimental paradigms of Stop-Signal and Stop-Change. In addition, certain individual peculiarities of the brain processes of people who participated in the research, including their gender identity in such functional states, are poorly studied.

Meanwhile, it is known from various literature sources (Bell et al., 2006; Li et al., 2009; Upadhayay et al., 2014; Korzhyk et al., 2017; Morenko, 2017) that the specificity of the brain processes of men and women is stipulated by different physiological features. Taking into account the ambiguity and insufficiency of the published literature data, we assume that complete inhibition of already initiated motor activity can occur with a different brain activity compared to that associated with the subsequent alternative motor response. On the way to clarify this issue, we aim to compare and establish the differences in the cortical electrical activity among women under the experimental conditions. In order to analyze the dynamic activity of the brain oscillatory systems, we plan to use the "event-related desynchronization/synchronization" (ERD/ERS) method, which is considered to be the most appropriate in terms of motor response (Pfurtscheller, Lopes da Silva, 1999; Pfurtscheller, 2001; Neuper et al., 2006). The detection by the above-mentioned method of the EEG markers of the brain processes related directly to the motor response to Stop and Stop-Change signals has not only fundamental scientific significance for the understanding of the mechanism of inhibition and switching of motor programs of targeted MM, but also of the obvious application associated with the improvement of early diagnostics of cortical dysfunctions of the neuromotor apparatus. 


\section{MATERIALS AND METHODS}

Participants. Forty-two women aged 18-23 years participated in the experiment. They did not have any neuropsychiatric disorders and traumatic brain injury in their anamneses, participated in the experiment on a voluntary basis, and corresponded to all common bioethical standards. The index of manual and auditory asymmetry was calculated for each participant, taking into account the nature of the responses in the survey and motor performance and acoustic tests (Zhavoronkova, 2009). Further studies involved right-sided testees whose coefficients of manual and auditory asymmetries were positive and were above $50 \%$. The total number of women was of 38 people.

The time of the sensory-motor response was determined by computer diagnostic complex "Diagnost-1" (Certificate of measuring equipment type No. UA-MI/2p- 2613-2008 0508 2008). According to the instructions, in the presence of a signal - geometric shape appearance on the screen, the examinee had to press and release the button panel as soon as possible.
EEG experiment procedure consisted of two consecutive sets. The first set envisioned the use of the Stop-Signal paradigm. The examinee was instructed to quickly press and release the left button of the console (Go-response) with the right index finger in the case of a low tone (sound of $600 \mathrm{~Hz}$ ). In the case of a high tone (1600 Hz sound), she had to stop pressing. Under experimental conditions, all stimuli sounds were served in pairs. In some stimuli pairs both sounds were low-pitched, in the others the first sound was a low tone and the second a high tone. Examinees in each case started moving right index finger at the first sound (Go). The second sound in the stimuli pair was important as either a confirmation of realization of the movement just begun, or of stoppage of the latter, i.e., the signal sequence corresponded to the StopSignal paradigm (Fig. 1A).

During the second set, the testees responded to a stimuli under the Stop-Change paradigm (Fig. 1B). In this case the appearance of $1600 \mathrm{~Hz}$ sound required rapid pressing and releasing of the right button of the console with the middle finger. In the case where the stimuli in the pair differed, the triggered motor program (for pressing

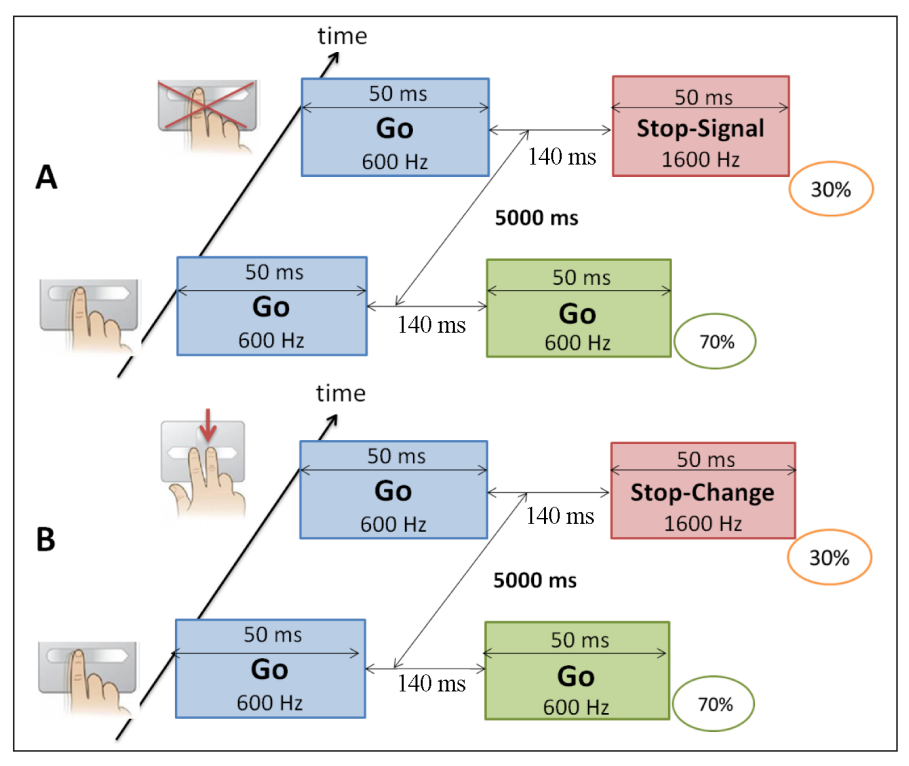

Fig. 1. Scheme of the conducted experiment paradigm Stop-Signal (A) and StopChange (B)

Go - the first sound in the stimuli pair, in response to which the examinee should start manual motion. Go, StopSignal, or Stop-Change - the second sound in the stimuli pair, confirms the initiated movement (Go), or stops the initiated movement (Stop-Signal), or stops the initiated movement switching to an alternative (Stop-Change). $70 \%$ and $30 \%$ - correlation between the stimuli pairs in the sample. 
the left button on the panel by the right-hand forefinger) should be inhibited with subsequent switching over to the alternative abovementioned program (Stop-Change).

Each acoustic signal lasted $50 \mathrm{~ms}$; the interval between stimulus pairs was $5.0 \mathrm{~s}$ long (Pfurtscheller, Lopes da Silva, 1999). The correlation of stimuli pairs with low sounds $(600 \mathrm{~Hz})$ and stimuli pairs with both low and high sounds $(600 \mathrm{~Hz}$ and $1600 \mathrm{~Hz})$ in the sample was $70 / 30$. Time delay after the first sound was $140 \mathrm{~ms}$. This period included a tactile (hidden) and partially motor components of sensory-motor responses related to the perception of signal analysis, the decision on the motion, and the formation of motor programs (Lyzogub et al., 2015; RangelGomez et al., 2015).

Registration and processing of EEG data. During the electroencephalographic stage, participants were in a specially equipped sound- and lightproof room, in a reclining position with eyes closed. EEG recording was performed using electroencephalographic hardware and software complex "Neurokom" (Certificate of compliance with technical regulations on medical devices No. 753 dated 25 January 2017). Monopolar EEG registration was performed with 19 active electrodes placed on the surface of the scalp on the international system 10/20. Combined ear electrodes A1 and A2, which were attached to the left and the right ear lobes, respectively, were used as reference electrodes. Additionally, referential electrodes Ref (placed between the frontal and the lateral parts) and $\mathrm{N}$ (Nasion) were used. Artefact activity rejection of native EEG was carried out by applying ICA-analysis (Independent Component Analysis).

Changes in brain activity were measured in the frontal (F3, F4), central $(\mathrm{C} 3, \mathrm{C} 4)$, and parietal (P3, P4) leads. The choice of such assignments is associated with existing published data that demonstrate the greatest part these cortical areas play in the processing of motor data and motor programming (Haaland et al., 2000; Ioffe, 2003; Bai et al., 2005; Neubauer et al., 2006; Morenko Korzhik, 2016).

Desynchronization (event-related desynchronization, ERD) and synchronization (event- related synchronization, ERS) of EEG frequency $(1 \mathrm{~Hz}$ to $35 \mathrm{~Hz}$ ) were estimated. Calculation of ERD/ERS maps was conducted in Matlab environment (MathWorks, 2015) in accordance with the procedure described by Pfurtscheller and Lopes da Silva (1999). The technique ERD/ ERS consisted of the following steps: (1) EEG data for $\mathrm{N}$ stimulus presentation was collected; (2) the signals were sequentially filtered for all stages $\mathrm{N}$ of analysis; (3) the filtered signals were summed in the square to calculate the signal strength for each reference in every stage; (4) the received power level for each period of time in the analysis stage was summarized for all stages (point-to-point); (5) the calculation of ERD/ERS was repeated for several consecutive frequency ranges in increments of $1 \mathrm{~Hz}$, and the received values were represented in a variety of colours of the spectrum that produced ERD/ ERS maps as a result. Each stage of analysis lasted $5 \mathrm{~s}$, which included $2 \mathrm{~s}$ before the submission of the second sound in the stimuli pair (reference interval, RI) and $3 \mathrm{~s}$ after the filing (post stimuli interval, PI). The change in spectral power EEG was evaluated in regard to a referential time interval (RI).

In each experimental set, the average percentage of false answers was determined among all possible ones (\%).

Statistical processing of the results. Test samples for normality of distribution were carried out using the criterion of Shapiro Wilk ( $W$, at $p>0.05$ ). The differences were evaluated by $t$ criterion of Student (for dependent samples). Differences at $p \leq 0.05$ were considered reliable. Changes in ERD/ERS of EEG frequency components in each lead between motor responses to significant stimuli under the conditions of the Stop-Signal and the Stop-Change paradigms were analyzed. Statistica 8.0 (StatSoft. Inc) and Matlab (MathWorks, 2015) software packages were used for statistical analysis.

\section{RESULTS AND DISCUSSION}

The duration of the sensory-motor response among women under examination was $382.67 \mathrm{~ms}$. The motor response in the set using the Stop- 
Change paradigm occurred with a relatively smaller number of mistakes, which obviously indicated greater concentration and attention of the individuals who participated in our research under the above-mentioned conditions (Fig. 2).

Among women, in both sets of the experiment the ERS phenomena predominated in the EEG a-range, which covered significant post-stimulation time periods that dominated during the sensory-motor response time of women. According to some authors (Neuper, Pfurtscheller, 2001; Pfurtscheller, 2001; Lopes da Silva, 2006), the synchronized activity in the EEG frequency spectrum corresponds to the transition to the deactivated state of the corresponding population of cortical neurons and can be traced in a state of reduced information processing, total or partial cessation of motor behaviour. In both sets of our experiment, this dynamics in the frontal-central and parietal parts could be due to the necessity of urgent stoppage of the activated motor program.

However, in the set of the Stop-Change paradigms, the generalized reduction of the ERS phenomena (PI: 0-820 ms) was observed at frequencies of $7 \mathrm{~Hz}$ (especially in the right hemisphere) and 9-10 Hz, compared to the one in the set with movement stoppage (Stop-Signal, $p \leq 0.05)$ (Fig. 3-5).

Such changes at a frequency of $12-13 \mathrm{~Hz}$ were recorded in the left central parts (PI: 310$1162 \mathrm{~ms}, p \leq 0.05), 15 \mathrm{~Hz}$ - right central parts (PI: $0-608 \mathrm{~ms}, p \leq 0.05)$. The corresponding results were associated with the fact that the synchronous interconnection between the main neural elements decreased (Pfurtscheller, 1999) and the level of activation of cortical parts involved in the implementation of the motor command increased (Steriade et al., 1990). It is worth noting a certain displacement of the corresponding processes from the right hemisphere (fixed at a frequency of $7 \mathrm{~Hz}$ ) to the left hemisphere (at a frequency of $12-13 \mathrm{~Hz}$ ), and again to the right hemisphere (at a frequency of $15 \mathrm{~Hz}$ ). Obviously, in terms of the Stop-Change response, such characteristic could reflect the formation of unstable and changing nature of cortical interactions among women in terms of active involvement of both hemispheres in information processing.

Unlike the set of the Stop-Signal paradigm application (ERS phenomena were observed, $p \leq 0.05$ ), in terms of Stop-Change response ERD of EEG in the right parietal part at a frequency of 9-10 Hz (PI: 0-736 ms) was determined, which was connected with increased spatial attention during motor response in the absence of visual control.

In the range of $\beta 1$ - activity in the sets of the experiment among women, we continued to record the predominance of EEG biopotential synchronization processes (Fig. 3-5). At the same time, in the set of the manual response to Stop-Change stimuli showed an increase in the ERS of EEG (PI: 0-280 ms, $p \leq 0.05$ ) at frequencies of $16 \mathrm{~Hz}$ in the parietal parts, at $19 \mathrm{~Hz}$ in cortical projections of the central and the parietal parts of both hemispheres, at $24 \mathrm{~Hz}$ in the left central part, compared to the use of the set of the Stop-Signal paradigm. Such principles may reflect local amplification of downward inhibitory impulses in the situation of the necessity for motor commands switching when one command must be inhibited and the other one, alternative, is activated.

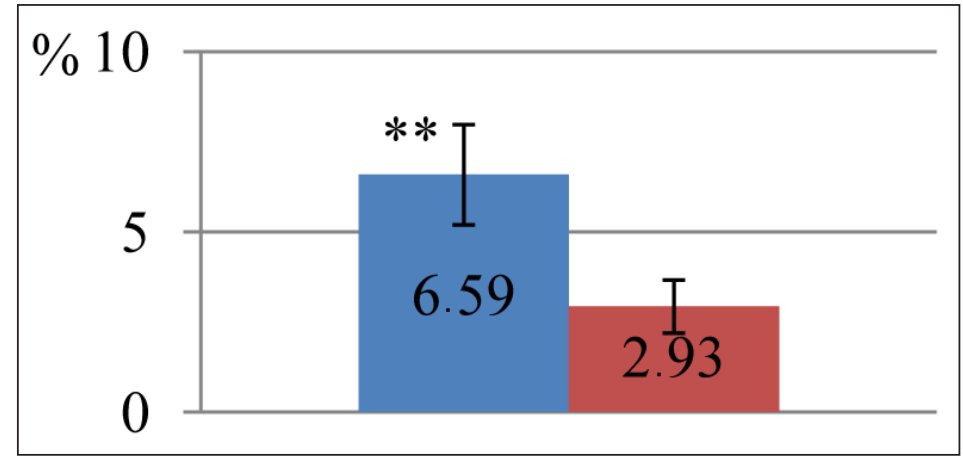

Fig. 2. The average percentage of mistakes made by women when responding to Stop stimuli (blue) and StopChange stimuli (red). ${ }^{* *} p<0.05$ 

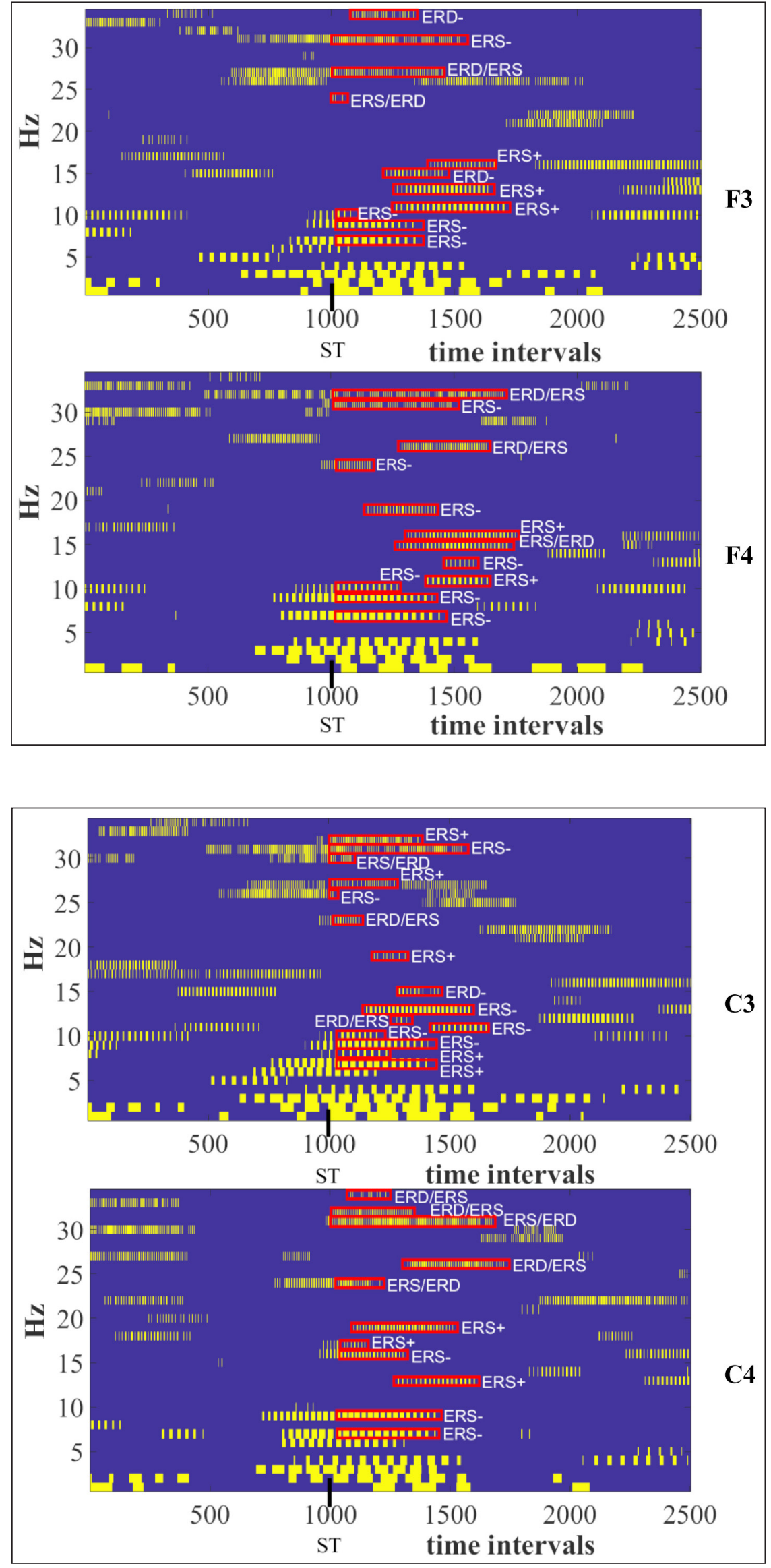

Fig. 3. ERD/ERS of the EEG frequency spectrum in the frontal parts during responses to Stop-Change stimuli compared to StopSignal among women
Fig. 4. ERD/ERS of the EEG frequency spectrum in the central parts during responses to Stop-Change stimuli compared to StopSignal among women 


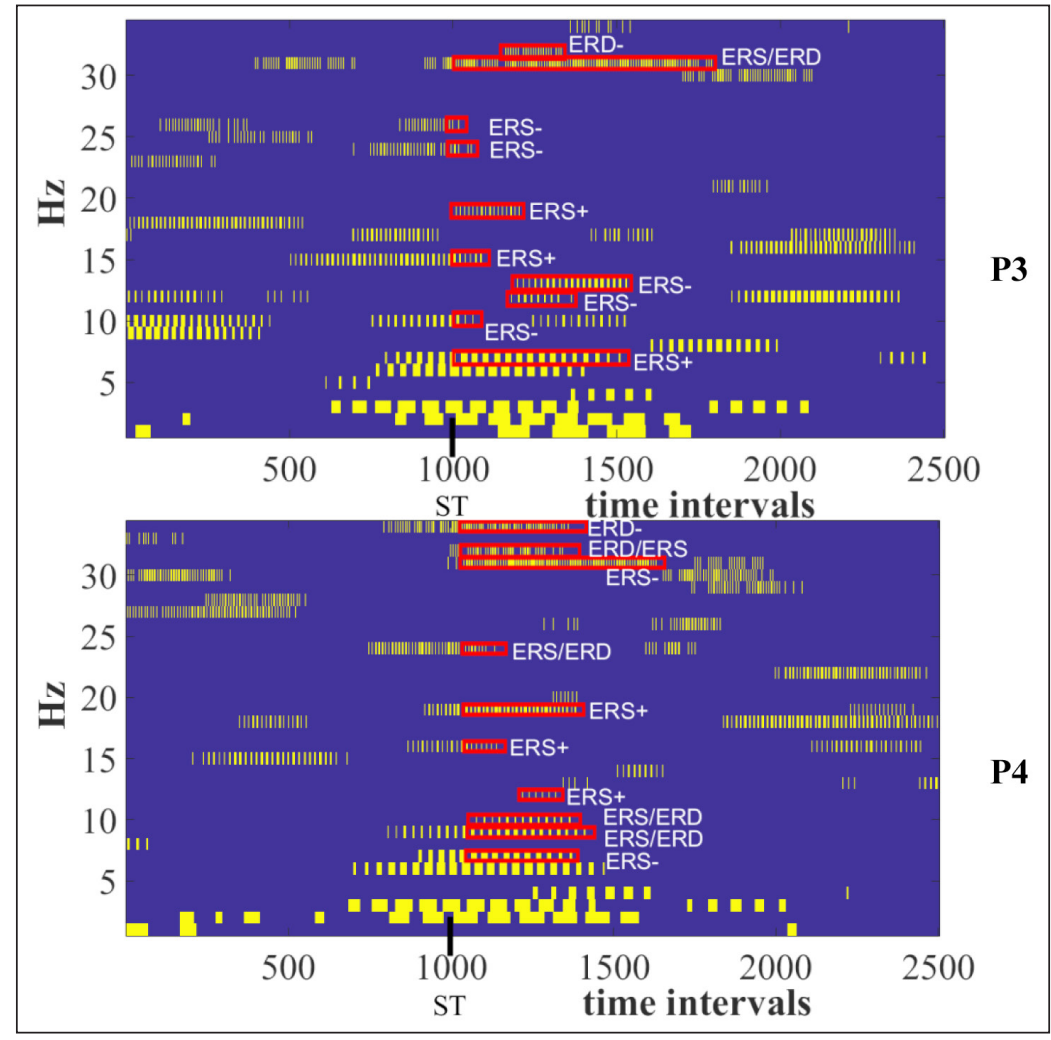

Fig. 5. ERD/ERS of the EEG frequency spectrum in the parietal parts during responses to Stop-Change stimuli compared to Stop-Signal among women

Notes to Fig. 3-5: - 500 time durations correspond to 1 s. A significant stimulus (ST) was given within the limits of the mark of 1000 time durations, depending on the experimental set.

- the yellow colour in a red frame in the figure indicates statistically significant differences $(p<0.05)$, and blue colour indicates their absence.

$-\mathrm{ERS} \pm$ or ERD \pm reflect the increase/decrease of the reaction to Stop-Change stimuli response compared to StopSignal, $p<0.05$. ERS/ERD (or ERD/ERS) in the figures indicate the change in the type of reaction to the Stop-Change stimuli (second from the pair) in relation to those on Stop-Signal, (first in the pair), $p \leq 0.05$.

We noted a spread of phenomena associated with the event of desynchronization in the StopChange paradigm at a frequency of $24 \mathrm{~Hz}$ (PI: $0-418 \mathrm{~ms}, p \leq 0.05)$ in symmetrical frontal, parietal and right central parts (Figs. 3-5). Such a principle was largely qualitative compared to the predominance of ERS in this EEG band in the set of the Stop-Signal paradigm use. From the researchers' point of view, the readiness for the activity, the information capacity (Thatcher et al., 1983), and the level of cortical neurons excitation increase in the desynchronized system (Steriade et al., 1990). Activation changes were revealed that apparently allowed increasing the differentiated attention and vigilance of the women to their action (Pulvermuller et al., 1997). We also assume that in terms of research, the processes of desynchronization at a frequen- cy of $24 \mathrm{~Hz}$ could be reflected in the activation of the cortical phenomena to some extent, related to the implementation of an alternative motor task.

Analyzing the obtained results, we should pay attention to the comparative increase of the EEG ERS during the time interval of about $1 \mathrm{~s}$, which was noted in the range of $7-8 \mathrm{~Hz}$ in the central and parietal parts of the left hemisphere (PI: 0-800 ms, $p \leq 0.05), 11 \mathrm{~Hz}$ and 12$13 \mathrm{~Hz}$ in the frontal and right central and parietal parts (PI: $572-1202 \mathrm{~ms}, p \leq 0.05$ ), and $16 \mathrm{~Hz}$ in the frontal parts (Fig. 3-5). In addition, there was a relative decrease in the ERD phenomena of EEG in the left frontal and central parts at a frequency of $15 \mathrm{~Hz}$ (PI: 582-876 ms, $p \leq 0.05$ ). Changes in such an extended time range are likely to indicate cortical processes that reflect 
not the motor response but its completion and the expectation of the next signal.

Certain instability of changes in the electrical activity in the $\beta 2$-range $(25-35 \mathrm{~Hz})$ was distinguished. According to the existing views (Logan et al., 1984), we assume that in terms of our research the processes of activation and inhibition of neuronal ensembles at such EEG frequencies occurred independently of each other and their success or failure may have been determined by the process that occurred first.

The obtained results established that women demonstrated a greater precision in performing the task in terms of the set of the Stop-Change paradigm use. This above-mentioned feature was obviously caused by a higher concentration and attention of women under given conditions. As a general regularity, in both sets of the experiment the predominance of phenomena related to the synchronization event in the range of $\alpha$ - and partially $\beta 1$-activity of the EEG was apparently associated with the inhibition of the activated motor program. Such processes were of a longer duration than the time sensory-motor response made by women and were noted after the completion of the latter. Meanwhile, in different sets of the experiment, cortical electrical activity acquired certain specific features of the frequencyspatial organization, which could indicate different brain processes during the response to Stop and Stop-Change stimuli. In the set of stoppage of the activated motor program MM and its switching to the alternative (the Stop-Change paradigm), a higher level of activation processes in the frontal, central, and parietal cortex areas in the EEG $\alpha$ - and $\beta$-activity range is generally shown among women who participated in the experiment.

\section{CONCLUSIONS}

1. It was established that women demonstrated greater precision in performing the task in the set with the Stop-Change paradigm.

2. A common feature in both sets of the experiment was the predominance of ERS events in the range of $\alpha$ - activity and partially of $\beta 1$ activity of EEG.
3. The participants' cortical activity connected with the stoppage of the activated motor program of $\mathrm{MM}$ and its subsequent switching to the alternative movement (Stop-Change paradigm) comparing to the complete stoppage of movement (the Stop-Signal paradigm) had significant distinctive features and was characterized by a specific frequency-spatial type of motor information processing, namely:

3.1. Generalized reduction of ERS in the cortex at the frequencies of the EEG a-activity, as well as an increase in ERD in the right parietal part $(9-10 \mathrm{~Hz})$ was established. The duration of such changes in the post-stimulation interval was longer than the duration of the sensory-motor response.

3.2. During the women's sensory-motor response, a growth of EEG ERS (0-280 ms) in symmetrical parietal $(16 \mathrm{~Hz})$, central and parietal $(19 \mathrm{~Hz})$ areas of the cortex was observed. The increase in ERD (0-418 ms) in the cortex, primarily in the right hemisphere, was detected at a frequency of $24 \mathrm{~Hz}$.

3.3. In the range of high-frequency activity (above $25 \mathrm{~Hz}$ ), the ERS/ERD spatial distribution acquired a volatile and changeable nature.

3.4. After the completion of the sensory-motor response (for about $1 \mathrm{~s}$ ), the ERS in the cortical parts in EEG $\alpha-(7-8 \mathrm{~Hz}, 11 \mathrm{~Hz}$, and 12$13 \mathrm{~Hz})$ and $\beta 1$-range $(15-16 \mathrm{~Hz})$ was revealed.

\section{ACKNOWLEDGEMENTS}

The research was carried out within the framework of the scientific theme "Neurophysiological mechanisms of human motor activity" of the Faculty of Biology of Lesya Ukrainka Eastern European National University.

Received 31 March 2018

Accepted 19 September 2018

\section{References}

1. Aron AR, Behrens TE, Smith S, Frank MJ, Poldrack RA. Triangulating a cognitive control network using diffusion weighted magnetic 
resonance imaging (MRI) and functional MRI. J Neurosci. 2007a; 27(14): 3743-52.

2. Aron AR, Durston S, Eagle DM, Logan GD, Stinear CM, Stuphorn V. Converging evidence for a fronto-basal-ganglia network for inhibitory control of action and cognition. J Neurosci. 2007b; 27(44): 11860-4.

3. Aron AR. From reactive to proactive and selective control: developing a richer model for stopping inappropriate responses. Biol Psychiatry. 2011; 69(12): 55-68.

4. Bai O, Mari Z, Vorbach S, Hallet M. Asymmetric spatiotemporal patterns of event-related desynchronization preceding voluntary sequential finger movements: a high-resolution EEG study. Clin Neurophysiol. 2005; 116(5): 1213-21.

5. Band GP, van Boxtel GJ. Inhibitory motor control in stop paradigms: review and reinterpretation of neural mechanisms. Acta Psychologica. 1999; 101(2-3): 179-211.

6. Bell EC, Willson MC, Wilman AH, Dave S, Silverstone $\mathrm{PH}$. Males and females differ in brain activation during cognitive tasks. Neuroimage. 2006; 30(2): 529-38.

7. Boecker M, Drueke B, Vorhold V, Knops A, Philippen B, Gauggel S. When response inhibition is followed by response reengagement: an event-related fMRI study. Hum Brain Mapp. 2011; 32(1): 94-106.

8. Chambers CD, Garavan H, Bellgrove MA. Insights into the neural basis of response inhibition from cognitive and clinical neuroscience. Neurosci Biobehav Rev. 2009; 33(5): 631-46.

9. De Jong R, Coles MG, Logan GD. Strategies and mechanisms in nonselective and selective inhibitory motor control. J Exp Psychol Hum Percept Perform. 1995; 21(3): 498-511.

10. Haaland KY, Harrington DL, Knight RT. Neural representations of skilled movement. Brain. 2000; 123(Pt 11): 2306-13.

11. Hummel F, Andres F, Altenmüller E, Dichgans J, Gerloff C. Inhibitory control of acquired motor programmes in the human brain. Brain. 2002; 125(Pt2): 404-20.

12. Ioffe ME. Neural basis of learning new movements: evolution of classical concepts. Journal of Higher Nervous Activity. 2003; 53(1): 5-21. Russian.

13. Jahfari S, Waldorp L, van den Wildenberg WP, Scholte HS, Ridderinkhof KR, Forstmann BU. Effective connectivity reveals important roles for both the hyperdirect (fronto-subthalamic) and the indirect (fronto-striatal-pallidal) frontobasal ganglia pathways during response inhibition. J Neurosci. 2011; 31(18): 6891-9.

14. Korzhyk O, Pavlovych O, Shvarts L, Shevchuk T, Dmytrotsa O, Poruchynskiy A, Morenko A. Event-related synchronization/desynchronization in terms of switch of manual motor programs in men. Biologija. 2017; 63(4): 297-305.

15. Krämer UM, Knight RT, Münte TF. Electrophysiological evidence for different inhibitory mechanisms when stopping or changing a planned response. J Cogn Neurosci. 2011; 23(9): 2481-93.

16. Li C, Zhang S, Duann J, Yan P, Sinha R, Mazure C. Gender differences in cognitive control: an extended investigation of the stop-signal task. Brain Imaging Behav. 2009; 3(3): 262-76.

17. Logan GD, Burkell J. Dependence and independence in responding to double stimulation: a comparison of stop, change, and dual-task paradigms. J Exp Psychol Hum Percept Perform. 1986; 12(4): 549-63.

18. Logan GD, Cowan WB, Davis KA. On the ability to inhibit simple and choice reaction time responses: a model and a method. J Exp Psychol Hum Percept Perform. 1984; 10(2): 276-91.

19. Lopes da Silva FH. Event-related neural activities: what about phase? Prog Brain Res. 2006; 159: 3-17.

20. Lyzogub VS, Kozhemyako TV, Yukhimenko LI, Khomenko SM. Electrophysiology characteristics of $\mathrm{P}_{300}$ and the functional organization of complex audiomotory reactions at adolescents. Cherkasy University Bulletin: Biological Sciences Series. 2015; 335(2): 72-8. Ukrainian. 
21. Morenko AG. EEG Activity during realization of manual movements by individuals with different characteristics of the alpha rhythm. Neurophysiology. 2017; 49(2): 143-50.

22. Morenko AG, Korzhik OV. Brain processes in women with different modal alpha-frequency through the execution of manual movements with applying of force. Biological Bulletin of Bogdan Chmelnitskiy Melitopol State Pedagogical University. 2016; 1: 326-41.

23. Neubauer AC, Fink A, Grabner RH. Sensitivity of alpha band ERD to individual differences in cognition. Prog Brain Res. 2006; 159: 167-78.

24. Neuper C, Pfurtscheller G. Event-related dynamics of cortical rhythms: frequency-specific features and functional correlates. Int J Psychophysiol. 2001; 43(1): 41-58.

25. Neuper C, Wörtz M, Pfurtscheller G. ERD/ERS patterns reflecting sensorimotor activation and deactivation. Prog Brain Res. 2006; 159: 211-22.

26. Pfurtscheller G, Lopes da Silva FH. Event-related EEG/MEG synchronization and desynchronization: basic principles. Clin Neurophysiol. 1999; 110(11): 1842-57.

27. Pfurtscheller G. Functional brain imaging based on ERD/ERS. Vision Res. 2001; 41(1011): 1257-60.

28. Pfurtscheller G. Quantification of ERD and ERS in the time domain. In: Pfurtscheller G, Lopes da Silva FH, editors. Event related desynchronization. Handbook of electroencephalography and clinical neurophysiology. Amsterdam: Elsevier; 1999. p. 89-106.

29. Pollok B, Gross J, Schnitzler A. How the brain controls repetitive finger movements. J Physiol Paris. 2006; 99(1): 8-13.

30. Pulvermuller F, Birbaumer N, Lutzenberger W, Mohr B. High-frequency brain activity: its possible role in attention, perception and language processing. Prog Neurobiol. 1997; 52(5): 427-45.
31. Rangel-Gomez M, Knight RT, Krämer UM. How to stop or change a motor response: Laplacian and independent component analysis approach. Int J Psychophysiol. 2015; 97(3): 233-44.

32. Ridderinkhof KR, Forstmann BU, Wylie S, Burle B, van den Wildenberg WPM. Neurocognitive mechanisms of action control: resisting the call of the sirens. Wiley Interdiscip Rev Cogn Sci. 2010; 2(2): 174-92.

33. Steriade M, Gloor P, Llinas RR, Lopes da Silva, Mesulam MM. Basic mechanisms of cerebral rhythmic activities. Electroencephalogr Clin Neurophysiol. 1990; 76(6): 481-508.

34. Thatcher RW, McAlaster R, Lester ML, Horst RL, Cantor DS. Hemispheric EEG asymmetries related to cognitive functioning in children. In: Perecuman A, editor. Cognitive processing in the right hemisphere. New York: Academic Press; 1983. p. 125-45.

35. Upadhayay N, Guragain S. Comparison of cognitive functions between male and female medical students: a pilot study. J Clin Diagn Res. 2014; 8(6): 12-5.

36. Verbruggen F, Logan GD. Models of response inhibition in the stop-signal and stop-change paradigms. Neurosci Biobehav Rev. 2009; 33(5): 647-61.

37. Verbruggen F, Logan GD. Response inhibition in the stop-signal paradigm. Trends Cogn Sci. 2008; 12(11): 418-24.

38. Verbruggen F, Schneider DW, Logan GD. How to stop and change a response: the role of goal activation in multitasking. J Exp Psychol Hum Percept Perform. 2008; 34(5): 1212-28.

39. Zhavoronkova LA. The right-handed and the left-handed: hemispheric asymmetry of the human brain biopotentials. Krasnodar: Jekoinvest; 2009. 
Olha Korzhyk, Olha Pavlovych, Olha Abramchuk, Tetyana Kachynska, Olena Dmytrotsa, Andriy Poruchynskiy, Alevtyna Morenko

\section{MOTERŲ SMEGENŲ PROCESŲ Y PATUMAI MOTORINIŲ PROGRAMŲ SUSTABDYMO IR PERJUNGIMO METU}

\section{Santrauka}

Tyrimo tikslas buvo nustatyti moterų elektrinès smegenų veiklos skirtumus kortikalinëje smegenų žievèje visiškai nuslopinus motorinès sistemos fizini judesi (MM, stop signalo paradigma) ir perèjus prie alternatyvių motorinių užduočių (stop perjungimo paradigma). Siekiant išanalizuoti smegenų svyravimo sistemų dinamini aktyvumą, buvo taikytas „su ivykiu susijusios desinchronizacijos / sinchronizacijos" (ERD/ERS) metodas, laikomas patikimiausiu MM metu. ERD ir ERS rodikliai buvo įvertinti EEG dažnio diapozone (1-35 Hz) priekinèse, centrinèse ir pariatalinèse linijose. Tyrimo metu tikslesni judesiai nustatyti stop perjungimo judesių serijose. Abiejose eksperimento dalyse vyravo ERS judesiai esant EEG $\alpha$ ir iš dalies $\beta 1$ aktyvumui. Skirtingose eksperimento dalyse kortikalinès žievès elektrinio aktyvumo specifinès dažnio ir erdvinès organizacijos savybès gali rodyti skirtingus smegenų procesus vykstant atsakui $\mathfrak{i}$ stop ir stop perjungimo stimulus. Stop perjungimo serijose stebima didesne EEG $\alpha$ ir $\beta$ aktyvacija priekinèje, centrinèje ir pariatalinèje kortekso dalyje.

Raktažodžiai: smegenų korteksas, sinchronizacija / desinchronizacija, fiziniai judesiai, stop signalo paradigma, stop perjungimo paradigma, moterys 